\title{
Risk Factors for the Sustainability of Medicinal Plants in Bhutan
}

\author{
Phurpa Wangchuk and Annette Olsen
}

\begin{abstract}
Medicinal plants are used worldwide in primary health care and also for modern drug discovery programs. More than 13,000 species of Medicinal and Aromatic Plants are used in traditional medicines and herbal cosmetics throughout the world and about 8000 of these are used in South Asia alone. In Bhutan, while the total number of species used by Local Healing System(s) is unknown, more than 500 species of medicinal plants are recorded in the pharmacopoeia of Bhutanese traditional medicine called g.so-ba-rig-pa (Sowa Rigpa). Currently 300 species, which grow in diverse ecological zones of the country, are used by the Institute of Traditional Medicine Services in formulating 98 different essential Sowa Rigpa medicines. In 2007, 16 tons of medicinal plants were procured by the institute alone and $85 \%$ of them, almost all wild species, were collected within the country. Unless properly managed, the sustainability of these wild medicinal plants is likely to be threatened. In this light, our paper describes the possible risk factors that may affect the sustainable use of medicinal plants in Bhutan. Four broad risk factors, which include biological, ecological, social and economic issues, are identified here. Our paper also throws light to the current policies, frameworks and acts that are put in place to ensure the sustainable use of medicinal plants in Bhutan and finally suggests future directions.
\end{abstract}

Keywords

Medicinal plants, vulnerability, sustainability, risk factors, Bhutan

\section{Introduction}

Medicinal plants are accredited by their users with mystical and supernatural powers of healing. They are used widely across the world for primary health care and also in modern drug discoveries. It is estimated that more than 13,000 species of Medicinal and Aromatic Plants (MAPs) are used in traditional medicines and herbal cosmetics throughout the world (Wilkinson and others, 2002). About 8000 of these MAPs are known in South Asia alone (Karki 2001).

In Bhutan, medicinal plants have become an indispensable tool for treatment regimens and income generation. Treatment regimens are available in two systems: g.so-ba-rig-pa (Sowa Rigpa) is a codified traditional medical system 
incorporated and integrated into the mainstream of national health care delivery services; and the Local Healing System(s) which are not documented but practiced countrywide (Wangchuk 2007). These traditional medical systems use medicinal plants as the main ingredients in their pharmacology.

While the species and the consumption pattern of medicinal plants are not determined for the Local Healing System(s), more than 500 species of medicinal plants are recorded in the pharmacopoeia of Bhutanese Sowa Rigpa medical system (Chophel 1993). As many as 300 species of medicinal plants, which grow in diverse ecological zones of the country, have been identified so far and more than 200 of them are currently used by the Institute of Traditional Medicine Services (ITMS) in the formulation of 98 different essential traditional medicines (Wangchuk 2004). In 2007, 16 tons of medicinal plants were procured by ITMS alone (Tenzin 2008) and $85 \%$ of them, almost all wild species, were collected within the country (Wangchuk 2006). An analysis of the current data shows that around $60 \%$ of the plant species collected within the country are harvested from about 3000 to 5500 metres above sea level and only $25 \%$ are collected from low altitude areas.

The collection, conservation and sustainable utilization of MAPs in Bhutan is guided by sound legal frameworks and acts: Forest Act 1969, Plant Quarantine Act of Bhutan 1993, Forest and Nature Conservation Act of Bhutan 1995, Environmental Assessment Act 2000 and Biodiversity Act and Framework of Bhutan 2003, 2006 (Yaganagi 2006; Tshering T 2006). Because of this, the biodiversity scenario in Bhutan is currently commendable and even flourishing. However, in spite of this, implementation of such legal frameworks is made difficult by lack of basic information on the biology, ecology and sustainability of MAPs in Bhutan. Apart from a few sporadic surveys and consumer chain analysis carried out by the Department of Forest (DoF), Medicinal and Aromatic Plant Section (MAP Section) and ITMS; not much research has been done on the natural products of Bhutan. Our paper is expected to add significantly to the information pool development in Bhutan. It describes the risk factors affecting the sustainable use of MAPs and provides some recommendations to enhance the sustainability of MAPs in Bhutan.

\section{Risk factors for the sustainable use of MAPs}

The sustainability status of the MAPs reflects a broader understanding of how biological, ecological, social and economic factors are intrinsically interconnected to conservation and development. The dynamics of MAPs sustainability and the associated risk factors are discussed in the light of this interconnected- 
ness. We have identified 10 risk factors (see Table 1), which are related to the sustainable use of MAPs in Bhutan. These risk factors broadly fall into four categories: biological, ecological, social and economical factors (see Table 1) which are discussed in detail here.

\section{Biological Factors}

Life Form: In general, harvesting interferes with the life cycle of the species. Life cycle characteristics of the species include phenology of flowering and fruiting, pollination, seed dispersal, species-species and species-environment interaction. However, the life cycle of many MAPs are often poorly known.

All the high altitude medicinal plant species are either monocarpic or polycarpic perennial herbs. The habitats of these species remain snow-covered from October to February. It appears as if the difficult environment, with its extremely short period for plant development is likely to give better chances for survival to perennial herbaceous plants than to annual species. However, in terms of production, the quantity of dried raw materials produced by these herbs, are far less than that produced by trees. For instances, 5,731 plants of Meconopsis horridula Hook.f. \& Thomson are required to get $57.31 \mathrm{~kg}$ of its dry material; 15,570 plants of Onosma hookeri Clarke need to be uprooted to get $33.32 \mathrm{~kg}$ of its dry root and 28,186 Nardostachys grandiflora DC. need to be uprooted in order to collect $39.46 \mathrm{~kg}$ of its dried roots (Shawe 1997).

The extraction of perennial plants before they reach sexual maturity increases the species vulnerability. The monocarpic species, such as Meconopsis horridula

Table 1. Four major risk factors (with their sub-categorisation) for the sustainable use of MAPs in Bhutan.

\begin{tabular}{ll}
\hline Major risk factors & Sub-category of risk factors \\
\hline Biological & $\begin{array}{l}\text { Life form. } \\
\text { Harvesting plant parts. }\end{array}$ \\
Ecological & $\begin{array}{l}\text { Habitat and population density of species. } \\
\text { Natural calamities and outbreak of fire. } \\
\text { Overgrazing. } \\
\text { Commercialization. } \\
\text { Economic }\end{array}$ \\
Multiple use and commercial diversification. \\
Poaching and illegitimate trade. \\
& Human population expansion. \\
& Access to markets.
\end{tabular}


need two years to reach the flowering stage and the individuals have to produce more offspring than required to replace them, since not all offspring will reach maturity. The plants die once they have produced flowers and set seeds. When such flowering plants are collected indiscriminately, the natural propagation process is interrupted, thereby inhibiting the individual plants from producing offspring.

The endangered perennial herbs Meconopsis horridula and Meconopsis simplicifoila (D.Don) Walpers produce seeds in large numbers, but germination and seedling recruitment are low, both in natural habitats and under laboratory conditions (Sulaiman and Babu 1996). Removing a large proportion of such species in one year is likely to have a significant impact on the species resiliency. The low seed germination, high seedling mortality and low productivity (quantity) will render most of the priority species endangered in the event of persistent collection.

Harvesting Plant Parts: The extraction of some plant parts has a bigger impact than others, i.e. taking roots are typically more damaging than taking seeds or flowers. It may affect the whole life cycle of the individual plants and produce a number of ecological impacts. For instance, persistent harvesting of the root of a single stemmed, sparsely distributed plant may threaten the survival of the species. The inappropriate harvesting methods of the tubers and bulbs of Onosma hookeri, Aconitum violaceum Jacq, Fritillaria delavayi Franchet and Dactylorhiza hatagirea D.Don or the uprooting of Meconopsis simplicifolia and Meconopsis horridula in order to collect the aerial parts obviously remove the whole individual and have a detrimental effect on sustainability. The uprooting of deep-rooted species in a fragile ecosystem would result in soil impoverishment by erosion and deprive the plants from their required nutrients. As a consequence of high frequency collection, the length of roots and volumes of root biomass are reduced. Similarly, the uncontrolled harvesting of the fruits of Terminalia chebula Retzius or seeds of Podophyllum hexandrum Royle can lead to decrease in seedling establishment. The over-harvesting of flowers of Gentiana robusta Hook.f. may result in fluctuations of species availability in the following years. The debarking of Fraxinus paxiana Lingelsheim may result into slow death of the whole plant.

Although the immediate result of indiscriminate harvesting of relatively small numbers of individual plants may not be visible, such practices can have a significant impact on long-term sustainability. On the other hand, for the formulation of traditional medicines; the harvest of roots, seeds and flowers of some species is unavoidable. However, for the last 11 years, the annual harvest of high altitude medicinal plants by ITMS has been claimed to be sustainable (Tenzin 2008), and the official harvest of high value species like Nardostachys grandiflora may be lower than what is illegally traded. 


\section{Ecological Factors}

Habitat and population density of the species: Studies on distribution patterns of medicinal plants were carried out in the neighbouring countries of India and Nepal but not much investigation has been carried out on distribution and population parameters of MAPs in Bhutan. The first scientific survey for high altitude medicinal plants was conducted in 1997. Only a few important species, based upon their global and perceived local threatened status, were studied at that time.

The plants in high alpine vegetation generally tend to form enormous root systems but hardly grow above the soil. One example of small plants with comparatively big roots is Gentiana urnula H. Smith, a species of 7 to $10 \mathrm{~cm}$ of height. Important medicinal plants such as Neopicrorhiza scrophulariifolia (Pennell) Hong, Onosma hookeri and Nardostachys grandiflora have comparatively large roots. Since the roots of these species are used in the traditional formulations, the whole plants are uprooted. These species are either restricted to alpine scree slopes or inhabit alpine meadows and slopes; all fragile environments. The uprooting damages their habitat and affects the growth of the population.

In general, most of the high altitude medicinal plant species occur in low frequency and density. Species with a higher density are mostly restricted to specific habitats. For example, Delphinium brunonianum Royle grows only in Chewla, north-west part of Bhutan in a small pocket area. Likewise, Meconopsis horridula inhabits only open alpine slopes.

The sustainable use of any plant species depends upon the renewal capacity of the population. To sustain a consistent population pattern, enough seeds or other reproductive material should be available for future regeneration. Although extraction of entire mature individuals does not necessarily reduce population size, ad hoc inappropriate collection practices exert a considerable influence upon the ecology and the sustainability of natural resources.

In the same way, harvesting a segment of the population may influence the population pattern. For instance, during a survey in 1997, Dactylorhiza hatagirea was found at 0.086 plants per $\mathrm{m}^{2}$ in their traditional collection site at Lingshi and the authors argued that harvesting may have contributed to the low density for this species (Shawe 1997). Currently, ITMS collects Delphinium brunonianum from only a few segments in Lingshi area. As indicated, D. brunonianum, grows only in restricted specialized ecological niches. The prolonged harvest of this species from the same locality would endanger the survival of the species in that locality. Species such as Gentiana urnula, Corydalis calliantha Long and Meconopsis horridula have a clumped distribution pattern. If they propagate vegetatively, harvesting part of the clumps may not significantly affect reproduction. 
Natural calamities and outbreak of fire: Like other Himalayan countries, the environment in Bhutan is highly vulnerable to erosion processes like glacial lake outburst, landslides, avalanches and soil erosion. Also, Bhutan is located in a volcanic zone and an eruption may be devastating for any life forms especially alpine herbs. Another destructive phenomenon is fire. Acres of forests are destroyed by fire in Bhutan and so vanishes the valuable medicinal plants. Fire management in Bhutan is made difficult by the rough rugged terrains and impassable ranges.

These natural phenomena contribute to the loss of some plant species in Bhutan. While some phenomena are beyond the control of human beings, at least fire can be prevented and controlled with information dissemination and appropriate fire control strategies and equipment engagement.

Overgrazing: Cattle, yak and sheep rearing is a significant economic mainstay of Bhutan. Overgrazing of the grasslands/forest by such animals, especially yaks, has a detrimental effect on the survival of the grazed plant species. Yaks consume every type of herbage vegetation apart from a few toxic species and are able to feed on very short growth (Gyamtsho 1996). They have an ability to negotiate narrow footpaths on rocky slopes and consume the herbs and grasses from isolated pockets. Unlike other grazing animals, they cover large areas of grazing ground every day. The intensity of yak overgrazing the alpine and temperate rangeland accelerates the rate of ecological destruction. For example, intense browsing by yaks checks the growth of seedlings of the Himalayan yew, Taxus baccata L. (Norbu 1996). The pastures around Laya, Lungo, Jarila and Lingshi are already affected by the grazing activities of large herds of yaks (Gyamtsho 1996).

Most of the important medicinal plants, e.g. Meconopsis horridula, Meconopsis simplicifolia, Fritillaria delavayi, Delphinium brunonianum and Corydalis calliantha in the country are restricted to delicate and specialized habitats. The intensive overgrazing activity, if not monitored, could lead to more habitat destruction and shrinkage of the natural population sizes of the valued medicinal plants. Besides, some plant species like Senecio and Ligularia which contain pyrrolizidine alkaloids that may be of medicinal values are found to be toxic to yaks and cattle (Winter and others 1994). Such poisonous plants are cleared by cattle herders in order to protect the cattle. This destructive act also significantly contributes to the extinction of many alkaloid-containing MAP species.

\section{Economic Factors}

Commercialization: The unpolluted environment and environmentally relatively friendly cultivation practices provide Bhutan with a unique advantage for 
marketing the MAPs and its derivatives. Many medicinal plants such as Aquillaria malaccensis Lamarck, Ephedra gerardiana Stapf, Rheum nobile Hook.f. \& Thomson, Rheum accuminatum Hook.f. \& Thomson, Neopicrorhiza scrophulariifolia, Nardostachys grandiflora, Aconitum spicatum (Bruehl) Stapf, Artemisia species, and Panax pseudo-ginseng Wall. sub sp. himalaicus H.Hara are in high demand for pharmaceuticals and have potential international market value (Ngawang 1996).

Bhutan has already legalized the trading of a few species like Swertia chirayita (Roxb.ex Flem.) Karsten and Piper pedicellatum DC. It is also rumoured that Neopicrorhiza scrophulariifolia and Nardostachys grandiflora are traded but there is no data to support this.

In the temperate and sub-tropical forests of Bhutan, logging activities are common. Although it is said to be managed properly, many valuable medicinal plants are destroyed in the process.

When economic forces become a reality, people's interest in maximizing their income could jeopardize their concern for a sustainable harvest of MAPs from the wild. Concomitant with the globalisation of market economics and increase in demand, the rate of demand and utilisation of MAPs will expand and their sustainability, especially the vulnerable species, can be threatened.

Multiple use and commercial diversification: The impact of multiple uses exerts intense pressure on some plant resources. The economically valuable plants are extensively used as incense, as fruits, as dyes, as resins, as vegetables and spices, as oils, as fodders, as firewood, in rituals and as ornamental plants. To date; about 181 fodder plants, 107 ornamental plants, 97 fruit and nut species, 77 forest vegetables, 40 aromatic plants, 36 natural dyes, 25 oil/resin species, 20 spice species and 12 food crops have been identified (Tshering D 2006) and most of them are also medicinal plants.

The local markets in Bhutan are flooded with MAPs like the roots of Nardostachys grandiflora, leaves and stems of Rhododendron ciliatum Hook.f, Rhododendron setosum D.Don, and aerial parts of Tanacetum nubigenum Wall for use as incenses. The Rhododendron and Nardostachys species are mixed together and widely used in religious rituals. Most of the raw medicinal species sold in the local markets as incense are often collected indiscriminately with no consideration for future regeneration. This trend may increase as more and more small-scale incense making industries and private sectors which are dependent on natural products are encouraged by the government. There are already 17 licensed incense entrepreneurs in Bhutan (Tideman 2006) and few natural products-based industries have come up over the last two years. It is reported that most of the raw materials currently used for incense making in Bhutan are imported from India. But it is more likely that illegal extraction and trade of the above selected incense plant materials is taking place. 
The stems of some medicinal plants like Juniperus squamata D.Don and Juniperus pseudo-sabina Fisch are commonly used as incense, as sacred artefacts for statues, and as firewood. Rhododendron anthopogon D.Don, Bombax ceiba L. and Cinnamomum granduliferum (Wall.) Meisn. are often cut down for use as firewood. The roots of Onosma hookeri and Rubia cordifolia L., important medicinal plants, are also used locally as natural dyes.

A number of medicinal plants are edible and serve as a food resource. This may be more common in rural communities. When rain does not fall, when the water becomes scanty and when the yield from the farmland cannot support their livelihood, rural farmers turn to the forest for food supplies. Fruits and nuts from Phyllanthus emblica L., Terminalia chebula, Terminalia bellerica (Gaertn.) Roxb. and Butea buteiformis (Voigt) Grierson \& Long are often eaten by rural people passing through the forests. Asparagus racemosus Willd., Adhatoda vasica Nees, Allium macranthum Baker, Taraxacum officinalis Wigg., etc are used as vegetables and spices. A few species of medicinal plants are used as tea leaf. The oil is sometimes extracted from the seeds and nuts of some medicinal plants. Some of these edible wild plants are occasionally marketed in the Thimphu vegetable market.

Nardostachys grandiflora, Rhododendron ciliatum, Rhododendron setosum, Hippophae rhamnoides L., Dactylorhiza hatagirea, Meconopsis horridula, Corydalis calliantha, Juniperus species, etc are considered important ornamental plants in Bhutan (Chhetri 1996). In fact, the Japan-Himalayan Company which was established in 1990 is the pioneer of this ornamental plant business in Bhutan and has exported Cupressus, Gaultheria, and Edgeworthia species to Japan at 60-100 yen per cutting (Chhetri, 1996). Many medicinal plants used by the ITMS are also part of the pharmacopoeia of the traditional medical systems of neighbouring countries and again this means extra value and more demand for these species.

As indicated above, many plants are used for multiple purposes. The intrinsic value of a plant becomes multiplied with its multiple uses thereby increasing the risk of over-exploitation. The market trends determine the market values of the plants. The intensity and impact of exploitation on those species could subsequently speed up with the rise in market value. Hence the multiple use and commercial diversification of medicinal plants, if extended and intensified, would surely have an impact on the sustainability of MAPs in Bhutan.

\section{Social Factors}

Poaching and Illegitimate Trade: Illegitimate harvest puts selective pressure on the species collected. These activities seem to have increased in recent years. 
Although illegitimate harvest and cross-border trade involves only a few species, high proportions are of conservation concern. For instance, Fritillaria delavayi is the subject of considerable cross-border trade. Because of high price and increased demand in other traditional medicine systems, these species are harvested illegally and are traded across the borders. Since they are uprooted, these species are highly susceptible to the impact of illegitimate harvest. Neopicrorhiza scrophulariffolia is also extensively collected. The rare species Nardostachys grandiflora and other medicinal plants like Rhododendron ciliatum, Rhododendron setosum and Tanacetum nubigenum are traded illegally as incense. While only parts are removed from some plants, many species like Nardostachys grandiflora, Neopicrorbiza scrophulariffolia and Fritillaria delavayi are uprooted. Aquillaria malaccensis Lamarck is poached for its resinous wood (locally known as Ar-nag) across the southern borders. The sparse data available on the amount of illegally harvested medicinal plants indicates that any species harvested illegally is at least harvested by factor ten of what the officially reported harvest rate should be (Shawe 1997). If the illegal activities are not controlled, the gradual disappearance of some species is likely.

Human Population Expansion: The current population of Bhutan is 646,851 and the fertility rate is 2.6 percent (Anonymous 2007). This figure looks small compared to the population of other countries. But given the small size of the country (38,394 square kilometres), the population is an issue of concern for Bhutan and it would inevitably increase pressure on the country's preserved natural resources including MAPs.

Human population density in Bhutan's high altitude regions, where the share of medicinal plant growth is high, is much lower than in neighbouring Himalayan countries. But even in those high altitude regions of Bhutan, the population has been rapidly increasing as a result of better child health care, improved nutrition and implementation of development activities. In fact, this segment of the population has an inherent impact on the MAPs of Bhutan exerted either through their settlement, livestock herding and farming practices or through the related economic activities.

Access to markets: Most of the areas where MAPs thrive abundantly are accessible only by foot and it often takes days or even weeks to reach them. Connecting those remote places with farm roads or even improving the existing mule tracks would facilitate the rural people to get to larger customers. In other words, the income of local communities from MAPs could rise with more access to markets. On the other hand, an easy access to valued medicinal plants could potentially affect their sustainability negatively. But an unambiguous delineation of land use rights for the local communities would support future sustainability of MAPs in Bhutan. 
In the face of income generation issues, many governmental institutions and non-governmental organisations are encouraging utilisation of biological resources especially MAPs resources, in Bhutan. The Marketing Sections at the ITMS and the Ministry of Agriculture are exploring markets for the natural products and are also disseminating the market information to the farmers and traders. While the information on market accessibility would give local producers and collectors a stronger bargaining power with the traders, it is more likely that the temptation to maximise profit will lead to the indiscriminate and unscientific collection of MAPs.

\section{Conclusion and future direction}

Our study identified 10 risk factors (see Table 1) for the sustainable use of MAPs in Bhutan. Among the four major risk factors, economical and social factors could be more detrimental to MAPs in Bhutan than the other factors. Nevertheless, they shouldn't be considered in isolation as these factors are interconnected and affect each others. Although risk factors put pressure on the sustainability of MAPs in Bhutan, sound policies on conservation, protection and management in the country are put in place to counterbalance this. It is an advantage that collection of medicinal plants by ITMS is regulated through "Special Permits" issued annually by the Department of Forest under the Ministry of Agriculture. Moreover, over the years MAP Section under the Ministry of Agriculture and ITMS have jointly initiated the MAPs domestication program and training of farmers on the "Good Collection/Harvesting Practices" and "Post Harvest Care". Recently, based on these cumulative farmer training experiences, MAP Section and ITMS jointly developed a "Guidelines for Identification and Collection of 26 Medicinal Plants (Krug and Milliken 2008) and it is expected to help in educating the collectors (farmers) of ITMS. In fact, some farmers are now more aware of MAPs sustainability and they use less destructive harvesting techniques. So, it can be hypothesised that if current demand and prices offered by ITMS remain at its current level, collectors might be more willing to protect their source of income against overexploitation.

The Non-Wood Forest Products (NWFP) Task Force (of which the first author is a member), has already endorsed the development of "National Strategy for NWFP Development in Bhutan (2008-2020)”. This body also started developing guidelines for resource assessment and their management of the economically potential species like Piper pedicellatum and Swertia chirayita. Those 26 prioritised species included in the "Guidelines for Identifica- 
tion and Collection of Medicinal Plants" (Krug and Milliken 2008) should be also included in the list of NWFP priority species and accordingly develop guidelines for resource assessment and their management. The identification of risk factors in the present study is expected to help in devising such strategic guidelines and management plans for other MAPs in Bhutan.

While it is the responsibility of the DoF to carry out resource assessment, inventories and develop management guidelines for NWFP in Bhutan; there are lots of challenges for them. They lack expertise concerning all the NWFP, especially MAPs, and this is complicated by the fact that there are huge numbers of NWFP species that cannot be handled by the limited staffs on hand. Hence, developing such guidelines and data pool for all the 300 MAPs is a Herculean task. Nonetheless, it can be initiated by different stakeholders.

Improvement in the sustainable use of MAPs will ultimately be largely determined by a consequently line of action from the implementing body. This line of action can only be achieved if adequate information exists on the MAPs' biological and ecological characteristics, the plants' vulnerability and on relevant socio-economic and political dynamics. In the absence of this information, the implementing body is faced with dilemmas over their decisions for utilisations of MAPs. It is therefore important to: conduct MAPs inventories, determine their abundance, gather ethno-medical and ethnobotanical information, assess the impact of current collection practices, enhance research into MAPs and establish databases.

Some legal frameworks concerning the MAPs and bio-prospecting need changes and in few cases even development of strategic utilization frameworks are necessary. Changes in the resource base combined with changes in operational rules would indicate adaptation and could render sustainable management probable, whereas a static rule system could be an indicator that adaptation to an inherently dynamic resource is not taking place; rules and physical attributes could be incongruent, leading to either inefficient use or depletion of the resources (Larsen 2002).

When the illegitimate poaching of high value MAPs are commonly taking place across-borders, it is appropriate to legalise these illegally traded species for collection by the Bhutanese. At least this way, the Bhutanese people can generate income and improve their livelihood.

All these gaps and challenges especially in terms of building standard information pool, research capacity, legal implementation, management and utilisation plans requires an urgent attention. This could be done successfully only if different MAPs stakeholders join forces. Examples of this are seen between ITMS and MAP Section which jointly domesticated and introduced a list of important species in different regions in Bhutan. In collaboration with ITMS, 
the MAP Section at Yusipang in the western region focuses on medicinal plants that grow in mid and high elevation, whilst the MAP Section at Mongar in the East concentrates on low altitude species. Consequently, the herb gardens were established at Lingshi ( 4000 meters above sea level) and at Lingmithang (600 meters above sea level). A germplasm collection of over 53 species has been established and a total of 13 species have been successfully propagated and subsequently distributed to farmers or planted out in on-station trials. While the compatibility of community development and the sustainable use of MAPs through such domestication are yet to be seen, it is definitely an optimistic indication that some domestication is possible and would reduce pressure on selected wild populations.

Therefore, there is an urgent need to strengthen similar collaboration and improve networks among the stakeholders encompassing farmers, government institutions, national and international organisations, NGOs and other agencies and projects involved in conservation and management of MAPs in Bhutan. In spite of all the emerging positive trends occurring inside these different organisations, there is not much cross-disciplinary collaboration or sharing of information. As a result, there are duplications in the MAPs initiatives thereby leading to wastages of government resources. For the success of any MAPs sustainability schemes and programs, it is also imperative that farmers, local healers, cattle and yak herders and relevant private organisations, who are directly or indirectly involved in MAP activities, are included in the decision making process.

From our experiences and also based on the experiences of Community Forest Management initiated by the Social Forestry Services; sustainability of MAPs would become more robust if government lands, which host MAPs, are leased to those enterprises dealing with MAPs. These enterprises may include government organisation, private enterprises and the rural communities or farmer associations. Included in the leasing agreements are accessibility rights and the responsibilities for proper management, conservation and utilisation; and these should be vigilantly monitored, evaluated and regulated by the responsible government organisations.

Bhutan is known for her richness in MAP resources and there is considerable potential for growth including that of bio-prospecting. However, many Bhutanese and also outsiders feel that not much has been utilised so far. Engaging the rural population in the MAPs business with strategic management and conservation plans would improve their livelihood. It is therefore, crucial to speed up research into domestication, cultivation and ecological sustainability of MAPs; reinforce in situ and ex situ conservation; enforce legal frameworks weighing beneficence over risks and allow sustainable utilisation 
of MAPs in Bhutan. While this paper is not focussed on economic issues, we may note that this would require substantial financing, and suggest that perhaps the revenue generated by eco-tourism could be used for rural community development through conservation, protection and enhancing the sustainable use of MAPs in Bhutan.

\section{Acknowledgements}

We are grateful to the ITMS for their support in publishing these findings. We also appreciate Mr. Ugyen (Ethnobotanist), Mr. Kinga Jamphel (Head of PRU), and the officials of the Ministry of Agriculture for their valuable comments. The authors would also like to thank Alex McKay and Geoffrey Samuel for their assistance in revising this paper for publication.

\section{References}

Anonymous 2007, Bhutan at a Glance 2007. National Statistical Bureau (NSB), Royal Government of Bhutan, Thimphu. Downloaded from http://www.nsb.gov.bt/index.php?id=15, 14 September 2011.

Chhetri, B.B. 1996, 'Vegetable oil and ornamental plants', Non-wood Forest Products of Bhutan. The Food and Agriculture Organization, Bangkok: Thailand, pp. 4-17.

Chophel,K. 1993, B.dud-rtsi-sman-gi-'khrungs-dpe-legs-bzhed-nor-bu' phreng-mzes. Bod-ljongme-dmang-dpe-skruen-khang publisher. Bod (Tibet), pp. 748-62.

Gyamtsho, P. 1996, Assessment of the condition and potential for improvement of high altitude rangelands of Bhutan, Zurich.

Karki, M. 2001, Medicinal and Aromatic Plants Program in Asia, IDRC /CRDI.

Krug, I. and Milliken, W. 2008, Guidelines for Identification and Collection of Medicinal Plants in Bhutan, Medicinal Plant Programme, Ministry of Agriculture, Thimphu, Bhutan.

Larsen, H.O. 2002, 'Commercial medicinal plant extraction in the hills of Nepal: Local management system and ecological sustainability', Environmental Management, 29: 88-101.

Ngawang, R. 1996, 'Medicinal plants', Non-wood Forest Products of Bhutan, RAP PublicationsFAO United Nations, Bangkok, Thailand.

Norbu, P.W. 1996, 'Basic information on Bhutan's Himalayan yew (Taxus baccata)'. Non-wood Forest Products of Bhutan, RAP Publications, FAO, UN, Bangkok, Thailand, pp. 1-3.

Shawe, K. 1997, Report of the Survey, Project ALA-92-22 (Unpublished official report). National Institute of Traditional Medicine, Ministry of Health, Thimphu, Bhutan.

Sulaiman, I.M. and Babu, C.R. 1996, 'Ecological studies on five species of endangered Himalayan poppy, Meconopsis (Papaveraceae)', Botanical Journal of the Linnean Society, 121:169-76.

Tenzin, S. 2008, 'Collection of medicinal plants and production of traditional medicines in Bhutan', Men-jong So-rig Journal. 1: 118-24.

Tideman, K. 2006, Bhutanese Incense Feasibility Study for Raw Materials Procurement, Processing, and Marketing in bulk in one Central Unit for all licensed Incense Manufacturers in Bhutan, SNV/Department of Industry, Ministry of Trade and Industry, Royal Government of Bhutan, Thimphu, Bhutan. 
Tshering, D. 2006, 'Foreword', Proceedings of the National Workshop on Development of Nonwood Forest Products in Bhutan, Forest Resources Development Division, Department of Forest, Ministry of Agriculture, Thimphu, Bhutan.

Tshering, T. 2006, 'The role of BAFRA in the conservation of medicinal resources', Proceedings of Bhutan-Japan Joint symposium on Conservation and Utilization of Himalayan Medicinal Resources, ITMS and SCDHMR, Thimphu, Bhutan, pp. 75-7.

Wangchuk, P. 2004, Bioactive Alkaloids from Medicinal Plants of Bhutan, M.Sc. Thesis, Department of Chemistry, University of Wollongong, Australia.

- 2006, 'Processing and utilization of NWFPs by Menjong Sorig Pharmaceuticals (ITMS)', Proceedings of the National Workshop on Development of Non-wood Forest Products in Bhutan, Forest Resources Development Division, Department of Forest, Ministry of Agriculture, Thimphu, Bhutan, pp. 92-7.

2007, 'Herbal remedies and utilization of medicinal resources in Bhutan', Book of Abstracts on International Workshop on Herbal Medicinal Plants and Traditional Herb Remedies. Hanoi, Vietnam, p. 6.

Wilkinson, J.A.; Wahlqvist, M.L. and Clark, J. 2002, New Food and Pharmaceutical Products from Agriculture, Rural Industries Research and Development Corporation, Australia, pp. $1-30$.

Winter, H.; Seawright, A.A.; Noltie, H.J.; Mattocks, A.R.; Jukes, R.; Wangdi, K. and Gurung, J.B. 1994, Pyrrolizidine alkaloid poisoning of yaks: Identification of the plants involved', The Veterinary Record, 134: 135-39.

Yaganagi, M. 2006, 'Bhutan's position on the access to biological resources and the protection of the associated traditional knowledge: The Biodiversity Act of Bhutan 2003', Proceedings of Bhutan-Japan Joint Symposium on Conservation and Utilization of Himalayan Medicinal Resources, ITMS and SCDHMR, Thimphu, Bhutan, pp. 17-28. 